University of Nebraska - Lincoln

DigitalCommons@University of Nebraska - Lincoln

Agronomy \& Horticulture -- Faculty Publications

Agronomy and Horticulture Department

1969

\title{
Productivity and the Morphology of Crop Stands: Patterns with Leaves
}

R. S. Loomis

University of California, Davis

W. A. Williams

University of California, Davis

Follow this and additional works at: https://digitalcommons.unl.edu/agronomyfacpub

Part of the Plant Sciences Commons

Loomis, R. S. and Williams, W. A., "Productivity and the Morphology of Crop Stands: Patterns with Leaves" (1969). Agronomy \& Horticulture -- Faculty Publications. 187.

https://digitalcommons.unl.edu/agronomyfacpub/187

This Article is brought to you for free and open access by the Agronomy and Horticulture Department at DigitalCommons@University of Nebraska - Lincoln. It has been accepted for inclusion in Agronomy \& Horticulture -Faculty Publications by an authorized administrator of DigitalCommons@University of Nebraska - Lincoln. 
Published in Physiological Aspects of Crop Yield: Proceedings of a symposium sponsored by the University of Nebraska, the American Society of Agronomy, and the Crop Science Society of America, and held at the University of Nebraska, Lincoln, Nebr., January 20-24, 1969. Edited by Jerry D. Eastin, F. A. Haskins, C. Y. Sullivan, C. H. M. Van Bavel, and Richard C. Dinauer (Madison, Wisconsin: American Society of Agronomy \& Crop Science Society of America, 1969). Copyright (C) 1969 American Society of Agronomy \& Crop Science Society of America. Used by permission. 


\section{Productivity and the Morphology of Crop Stands: Patterns With Leaves}

R. S. LOOMIS and W. A. WILLIAMS

University of California

Davis, California

The primary productivity of communities made up of autotrophic green plants is initially dependent upon photosynthesis. The patterns of chlorophyll display at each level of community organization reveal features which can be related to light interception and photosynthetic activity, and hence, to production. Studies on the comparative morphology of such displays should reveal principles useful for designing more efficient crops. It is important that we identify these principles since existing patterns are not necessarily the most efficient for intensive agriculture-a consequence of natural selection, even under strong influence of man, having occurred principally in poverty environments and having emphasized many parameters of fitness in addition to primary productivity.

The most detailed information about chlorophyll patterns is perhaps available at the cytological level. The elements of the patterns at this level include the arrangement of pigment molecules into basic photosynthetic units, with apparatus for charge separation and for compartmentalization of products, reactants, and enzyme systems. It appears that the apparatus is basically similar for all species, at least among higher plants, although important differences in carbon pathway and chloroplast structure have been revealed for major ecological groups.

At a higher level, we know less about how patterns in leaf anatomy, Including chloroplast localization within cells, relate to basic capability for assimilating $\mathrm{CO}_{2}$ Light distribution within the leaf and resistances to gaseous fluxes are involved and these aspects vary with environment, as between sun and shade positions within a canopy (Björkman and Holmgren, 1963).

Our attention will be focused here on the patterns apparent at a yet higher level of organization-the assemblage of photosynthetic elements within plant communities. It appears legitimate to speak of a morphology at this level-indeed, also of the ontogeny and phylogeny of the pat- 
terns. The impetus for research on such patterns comes from two sources. One is the increasing recognition by ecologists of the importance of primary production in the functioning of ecosystems. The second is from agriculturalists. As limitations related to pests, nutrients and water are alleviated, more attention to basic limitations on yield has been required, i.e., to the production capabilities of the plant communities. Although canopy architecture may affect productivity in various ways, our discussion will be directed principally towards its influence through light distribution.

\section{COMMUNITY ORGANIZATION}

\section{A. Density of the Vegetative Cover}

The most obvious feature of foliage canopies as related to production is the density of the foliage canopy. Ecologists have long made a practice of estimating percent cover and of relating this to production. Less than full cover permits solar radiation to escape interception by the photosynthetic apparatus. This is a problem of considerable importance with cultivated crops during early stages of growth. As examples, Shibles and Weber $(1965,1966)$ and Williams et al. (1965a) found that when cover is scant, production is directly related to the fraction of light intercepted. With annual crops, it usually takes a very long time for even a densely sown crop to achieve as much as $75 \%$ interception (Santhirasegaram and Black, 1968).

Chlorophyll and leaf area indices have both been used to characterize the amount of photosynthetic material in the cover. Aquatic ecologists (e.g., Steeman Nielsen, 1957; Talling, 1961) pioneered in the use of chlorophyll estimation to describe the community. The result was that depth distributions of chlorophyll, light, and production rate were found to be roughly related, but not well enough to estimate standing crop or metabolic density from chlorophyll indices (Goldman and Carter, 1965). Chlorophyll indices have been measured for a number of terrestrial communities (Brougham, 1960; Bray, 1960; Okubo et al., 1968), but correlations with production are generally poor.

For both aquatic and terrestrial systems, photosynthetic capability of the elements increase with chlorophyll concentration up to a saturation level (Gabrielsen, 1948). This level for leaves is about $3 \mathrm{mg}$ chlorophyll $(\mathrm{a}+\mathrm{b}) \mathrm{dm}^{-2}$. surface. At this level, changes in chlorophyll concentration strongly affect the extinction coefficient of the leaves, but the absolute amount of light absorbed is little affected (Kasanaga and Monsi, 1954). Most higher plant leaves contain at least the level of chlorophyll required for saturation of their $\mathrm{CO}_{2}$ assimilating capacity, and the "excess" chlorophyll is not correlated with production. Further, the response of a leaf in assimilating $\mathrm{CO}_{2}$ becomes a diminishing returns response with increasing light flux (Fig. 3-5, left). Thus, chlorophyll indices require, for quantitative purposes, the application of two curvilinear relations. When one considers that the distribution of chlorophyll of higher plant leaves is essentially in sheets whose surfaces 
(epidermis) are restrictive to $\mathrm{CO}_{2}$ exchange, and whose lateral dimensions largely determine light interception, it becomes clear that area indices of leaves are a more functional basis for describing canopy morphology.

The use of leaf area as the description parameter was pioneered by English scientists who applied the techniques of "growth analysis" to agricultural communities. They were led to the concept of crop growth rate ( $\mathrm{C}$, net dry matter production) being equal to net assimilation rate of leaves ( $\mathrm{E}$, mean rate of net photosynthesis of all leaves) times the leaf area index ( $\mathrm{L}$, area of leaf per unit area of ground).

$$
\mathrm{C}=\mathrm{EL} \text {. }
$$

Considerable attention has been given to variations in $\mathrm{E}$, but this is a dependent variable and is not particularly useful in community analysis except to consider its rate of decline with increasing $L$; its value is always small at the highest values of $\mathrm{C}$. However, this approach also caused a focus on $L$ as a parameter of community structure, and the leaf area index of Watson (1947) has become a basic description tool.

When $\mathrm{C}$ is related to total leaf density, $\mathrm{L}$, two kinds of relationships have been found. In one, $C$ increased as $\mathrm{L}$ increased up to some optimum value of $\mathrm{L}(\mathrm{L}$ opt), and then declined (Watson, 1958; Black, 1963). In the other cases, a plateau response has been found with $\mathrm{C}$ remaining constant as L increased (Brougham, 1956; Shibles and Weber, 1965; Williams et al. 1965b). The breaking point of such curvesgenerally occurs at an $L$ level sufficient to provide full cover. This level has been designated $L_{c r i t i c a l}$ or $\mathrm{L} 95$ (L required to intercept $95 \%$ of sunlight) by some workers. Watson and his associates have related seasonal yields to leaf area duration, D, the integral of L over time, but it appears to us that the integral of percent cover would be a better index.

\section{B. Horizontal Patterns Among Leaves}

Full cover could be provided by one continuous sheet of leaves. However, horizontal distributions are such that $\mathrm{L}=3$ or more is needed for complete interception of light. Leaf distributions may range from uniform (with regular or mosaic patterns), to random, and to contagious distributions (clumped or aggregated patterns). Greig-Smith (1964) summarizes a number of techniques for determining the type of pattern. The quadrant size and variance-mean ratio techniques are worthy of comment.

Contagious and regular patterns in foliage may be of several size scales. The individual plants, branches, leaves, and leaflets each serve as aggregation centers in contagious patterns. By varying the size of a series of quadrats for systematic sampling, one can deduce the aggregate sizes from the variance among quadrats. However, it is most convenient to increase quadrat size in a geometrical series, and this results in low sensitivity (Kershaw, 1957).

The variance mean ratio technique based on inclined point quadrats 
T'able 3-1-Proportions of gap and variance-mean ratios (relative variance) to vertical point quadrats for six model stands of Lhorizontal $=1$

(Warren Wilson, 1967)

\begin{tabular}{cccc}
\hline & \multicolumn{2}{c}{ Proportion of gap } & Relative \\
\cline { 2 - 4 } Stand & Observed & $\begin{array}{r}\text { Expected } \\
\text { if random }\end{array}$ & $\begin{array}{c}\text { Reliance } \\
\text { variance }\end{array}$ \\
\hline 1 & 0.22 & 0.37 & 0.49 \\
2 & 0.31 & 0.37 & 0.74 \\
3 & 0.37 & 0.37 & 0.98 \\
4 & 0.42 & 0.37 & 1.20 \\
5 & 0.48 & 0.37 & 1.53 \\
6 & 0.57 & 0.37 & 1.96 \\
\hline
\end{tabular}

has been employed by Warren Wilson $(1959,1961,1965)$. His method, with vertical points as an example, consists of comparing ratios of the variances of foliage contacts to their means. Mean and variance are equal in Poisson distributions (ratio equals 1.0). Experimental ratios less than 1.0 indicate regular distributions, and those greater than $\mathbf{1 . 0}$ indicate contagious distributions. A number of interesting observations with this technique were made by Warren Wilson. In pure stands, leaf distributions for white clover (Trifolium repens L.) and English ivy (Hedera) were strongly regular, and for grasses such as Lolium were strongly contagious (Warren Wilson, 1967). When mixed in swards, clover and ryegrass (Lolium spp.) tended individually to be random; but collectively they were regular (Warren Wilson, 1959). Thus, various species were not independently arranged, and distribution of the subordinate species occurred in the gaps of the dominant grass.

Further, different patterns may be revealed with different inclinations of the quadrat (Warren Wilson, 1965). Alfalfa foliage (Medicago sativa L.) was random to points between 0 and $60^{\circ}$ elevation, but contagious at higher angles. Warren Wilson concluded that this was due to plants being erect causing leaves to occur in vertical columns. Vertical points sampled either dense or less dense regions, whereas inclined points averaged these regions.

The implications of variations in pattern to productivity can be seen in Table 3-1 where observed and expected (from random basis) proportions of gaps are given for six of Warren Wilson's model canopies with horizontally displayed $L=1$. Gaps to vertical points range from 22 to $57 \%$ of the ground area for variance ratios characteristic of real communities. It seems that the contagious pattern of grasses is relatively inefficient in light interception per unit L. However, Saeki, Iwaki, and Monsi (Monsi, 1968) have proposed a "cluster" foliage model as being particularly efficient. The argument is that widely dispersed clusters of leaves would have a smaller extinction coefficient than would dispersed foliage, and hence more leaves could be illuminated at large L. As $\mathrm{L}$ increases, the additional leaves are added to existing clusters; thus the extinction coefficient decreases with increasing $L$ as proposed by Verhagen et al. (1963) for an ideal foliage.

Warren Wilson (1961) comments that while the clumping of grasses is offset to some extent by a narrow width of leaves and the tendency of 
the clumps to open upwards, the clumping could represent an adaptive feature to xeric environments.

With agricultural crops, a basic pattern is imposed upon the community by grouping plants in rows or other regular patterns, and by controlling the population density. This has certain obvious influences on canopy morphology, particularly in affecting the time to achieve full cover and in introducing a hedgerow characteristic to the surface of the canopy. Some of these influences have been examined experimentally (e.g., Shaw and Weber, 1967; Baker and Meyer, 1966; Heinicke, 1963) and theoretically (Jahnke and Lawrence, 1965). One general conclusion is that north-south rows give a better pattern of light interception and higher yields than do east-west rows. Optimum row spacing will be influenced by the potential size and character of the individual plants, and by latitude. In the discussion which follows, our attention will be given principally to variations in pattern found when plants are uniformly or randomly spaced.

\section{Vertical Separation of Leaves}

The influence of variations in the vertical density of leaves is also relatively unexplored. Nichiporovich (1961) has discussed this in relation to skylight occlusion by a leaf of a given width (w) and various distances (d) from a receiver point. The occluded solid angle $\gamma=2 \tan ^{-1}$ (w/2d) (Fig. 3-1, left). Since the tangent function is hyperbolic, one can determine a breaking point in the curve of $\gamma$ versus $w / d$; at $w / 2 d=$ $0.5,53^{\circ}$ or about one-third of the sky is occluded whereas, at $w / 2 \mathrm{~d}=$ $0.25, \gamma=28^{\circ}$. Further decreases in $w / d$ narrow $\gamma$ only slowly. Thus, leaf size in relation to vertical separation strongly influences the solid angle occlusion and hence the skylight pattern within a canopy. Large but widely separated leaves like those of sunflower (Helianthus annuus L.) may actually create a diffuse light pattern quite similar to a shorter community with small leaves like alfalfa (Anderson, 1966b). Most plants seem to have evolved with mechanisms for maintaining $d<2 \mathrm{w}$ $\left(\gamma=28^{\circ}\right)$, but in breeding for dwarf varieties of cultivated species the relation has been overlooked. Thus, the short internode types of grain sorghum (Sorghum vulgare Pers.) frequently have their wide leaves very close together in relation to width. "Better" canopy structure would result if leaf width was reduced or if the leaves were whorled to reduce the contagious distribution resulting from the opposite and alternate arrangement.

The same geometry applies to gap size (Fig. 3-1, right). From earth, the sun's disc subtends a mean solid angle of $32^{\prime}\left(\mathrm{ca} \cdot 0.5^{\circ}\right)$. Thus a gap admitting direct sun to a leaf low in the canopy must have a solid angle to that receiver point of greater than $0.5^{\circ}$ to admit the full flux of direct sun. Gaps with widths (w) less than about 0.01 of the distance (d) between gap and receiver point $\left(\tan 32^{\prime}=0.0093\right)$ will produce sunflecks of varying illuminances less than direct sun. This is particularly evident in deep woodland canopies where sunflecks as bright as full sun may be rare (Evans, 1966). The same situation would occur in herba- 

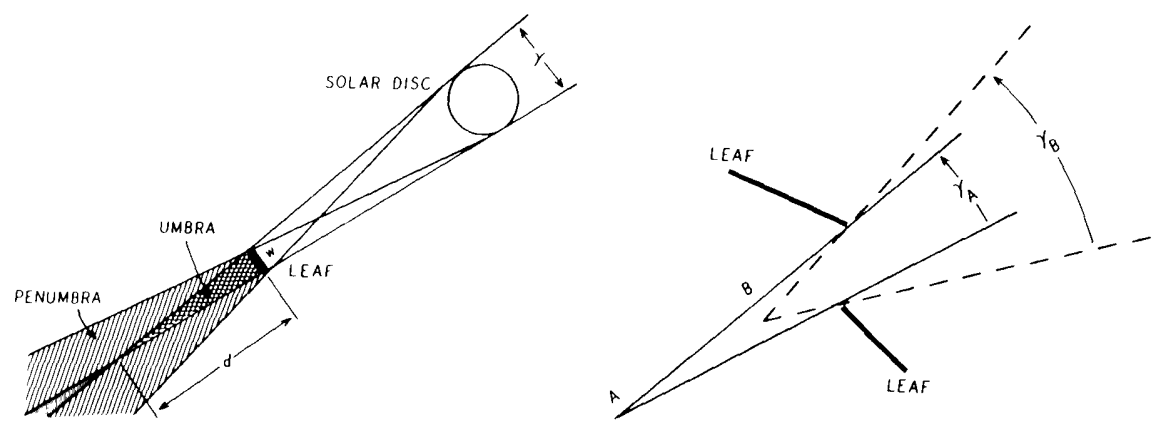

Fig. 3-1-Geometry of gaps and penumbra in relation to the distance between leaves. Left: Diffusion of shadow edges by penumbral effects. The angular width of the penumbra is 32 '. 'The same model can be used to visualize the portion of sky (solid angle, $\gamma$ ) occluded to a receiver point distance d from a leaf of width w. Right: Angular size of gaps $(\gamma)$, admitting direct and diffuse sunlight to receiver points $A$ and $B$, in relation to separation of leaves. With $\gamma$ less than $32^{\prime}$, the full dise of the sun will not be seen at the receiver point and sunflecks of varying irradiances result.

ceous stands scaled to have dense canopies of small or finely divided leaves. The finite size of the sun also causes penumbral effects on shadows (Fig. 3-1, left). If the solid angle of the sun is $0.5^{\circ}$, then the penumbra has a width of about 0.01 of the distance from shading leaf to the receiver. If leaves are widely spaced vertically or are very narrow [as with conifers and asparagus (Asparagus officinalis L.)] shadow edges will be quite diffuse - in fact all distinctions between sunlight and diffuse light may be lost. Duncan et al. (1967) point out that their theoretical model will not simulate such light environments, and, as far as we know, this feature has not been included in any model.

\section{Vertical Distribution of Leaves and Light Interception}

Monsi and Saeki (1953) introduced to the western world the idea of measuring for herbaceous communities the amount of leaf area in each of several horizontal strata. This has been an especially powerful approach since, analogous to algal suspensions, it was found that light attenuation at any depth can usually be related to interposed $L$ by a simple analytical expression, the Bouguer-Lambert law:

$$
\mathrm{I}=\mathrm{I}_{\mathrm{O}} \mathrm{e}^{-\mathrm{KL}} \text {, }
$$

where $I$ and $I_{0}$ are light fluxes to horizontal receivers at points within and above the canopy, $\mathrm{L}$ is leaf area index from the top of the canopy, and $\mathrm{K}$ is an extinction coefficient. Variations in $\mathrm{K}$ have been related to variations in canopy structure, especially to angle of leaf display (Monsi and Saeki, 1953; Kasanaga and Monsi, 1954; Monsi, 1968; Loomis et al., 1968; and Takeda, 1961; among others). This relationship is well illus- 

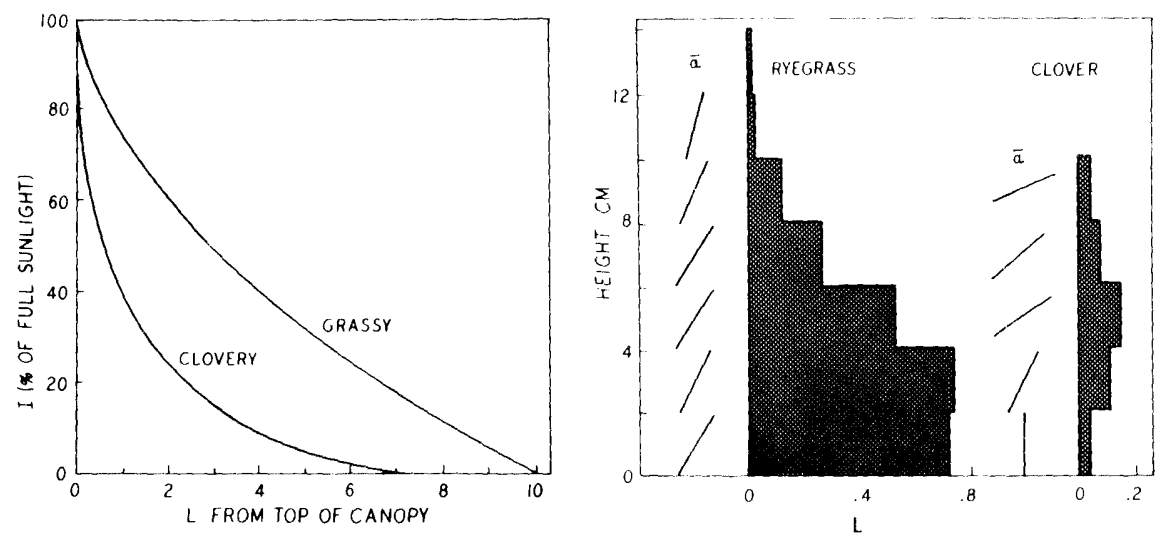

Fig. 3-2-Left: Attenuation of sunlight in clovery and grassy swards as a function of L(after Stern and Donald, 1962). Right: Vertical distribution of $\mathrm{L}$ and mean foliage angle $\bar{a}$ as determined with point quadrats for ryegrass and clover (after Warren Wilson, 1959).

trated through the comparative morphology of ryegrass and subterranean clover (Trifolium subterraneum L.) stands. Stern and Donald (1962) found that sunlight was diminished much more strongly per unit LAI in clovery stands than in grassy stands (Fig. 3-2, left). Approximate extinction coefficients calculated from these data are 0.60 for clover and 0.25 for grass.

Warren Wilson (1959) used the frequency, with which horizontal and vertical needles contacted leaves on passage through various strata of closely analogous stands, to estimate the mean foliage angle, $\bar{\alpha}$. His results (Fig. 3-2, right) illustrate clearly the difference in display by such species which account largely for the differences in light attenuation-perennial ryegrass tends toward erect leaves and white clover toward horizontal leaves.

\section{E. Foliage Angle}

Mean foliage angle alone may not provide an adequate description of the canopy morphology for some communities. The distribution of $\alpha$ should also be known. Nichiporovich (1961) and deWit (1965) obtained distributions of leaf angle weighted by area for entire canopies (without measuring vertical distribution).

These foliage descriptions serve to characterize some major differences in canopy morphology. For example, Nichiporovich found cucumber (Cucumis sativus L.) and clover to be highly planophile (horizontal leaves predominating) in contrast to timothy (Phleum pratense L.) and maize (Zea mays L.) with erectophile canopies. His distribution for maize corresponded to the surface elements of a sphere.

He concluded that such a distribution with $L=4$ would be optimal, but his supporting argument, based principally on the spherical distri- 
bution providing the minimum leaf area for intercepting skylight, is unconvincing. While it is true that a spherical distribution permits the display of elements normal to the light from each region of the sky (2 times over with $\mathrm{L}=4$ ), the flux of skylight is not received uniformly from all sky zones, and it is usually small relative to direct sunlight. Furthermore, in the lower stories of canopies, the probability of a gap to the sky at agiven angle of elevation is proportional to the size of that angle (i.e., inverse to the chance for leaves to occur in the light path.) As may be seen clearly in upward fish-eye views through canopies, gaps occur principally near the vertical (Anderson, 1966b). When light from near the zenith is relatively abundant, and with erect leaves in the upper strata providing abundant gaps, horizontal leaves in the lower strata may be useful. This could yield a spherical distribution-but for reasons other than those stated by Nichiporovich.

It is interesting that such "vertical-to-horizontal" structure has been suggested frequently (Watson and Witts, 1959; Verhagen et al., 1963; Blackman, 1962) as an efficient pattern, yet tests with models have failed to confirm the view (Loomis et al., 1967).

Canopy morphology may vary widely for a particular species as illustrated in Fig. 3-3, left, by comparisons of several fully developed maize crops. The Russian (R) and Estonian (E) communities were strongly erectophile, the Netherlands (N) one weakly plagiophile (median angles dominant), while those from Davis, California (D) were strongly planophile. Udagawa et al. (1968) describe a strongly plagiophile maize community. Genotypes and environments were all different; and it cannot be determined from the original publications whether similar stages of development and densities are compared. Yet, it is evident that the range of distributions observed for this one species is very great.

Herbaceous communities also may show marked changes in canopy structure during growth. Particularly striking are deWit's (1965) data for perennial ryegrass (Fig. 3-3, right), in which the proportion of horizontal leaves increased during growth. The changes for maize are less dramatic. Loomis et al. (1968) noted that the upper leaves of maize shifted to a more horizontal habit after tasseling, but the maize variety studied by Ross and Nilson (1967b) increased in percentage of erect leaves while the proportion at medium inclinations decreased at about the same stage of growth. In comparison, the maize communities studied by Udagawa et al. (1968) and deWit (1965) changed less during development; the same seems true for sugar beet (Loomis et al., unpublished). Nevertheless, structural changes between juvenile and mature canopies are obvious for many species. In particular, dicotyledonous species frequently show an early dominance of horizontal leaves-an advantageous feature for maximizing light interception by the small leaf area displayed by young crop stands.

\section{F. Stratified Analyses of Foliage Angle}

Only two extensive studies with stratified analyses of leaf angle distributions are known to us. Loomis et al. (1968) reported on time course changes in maize over a wide range of population densities, and 

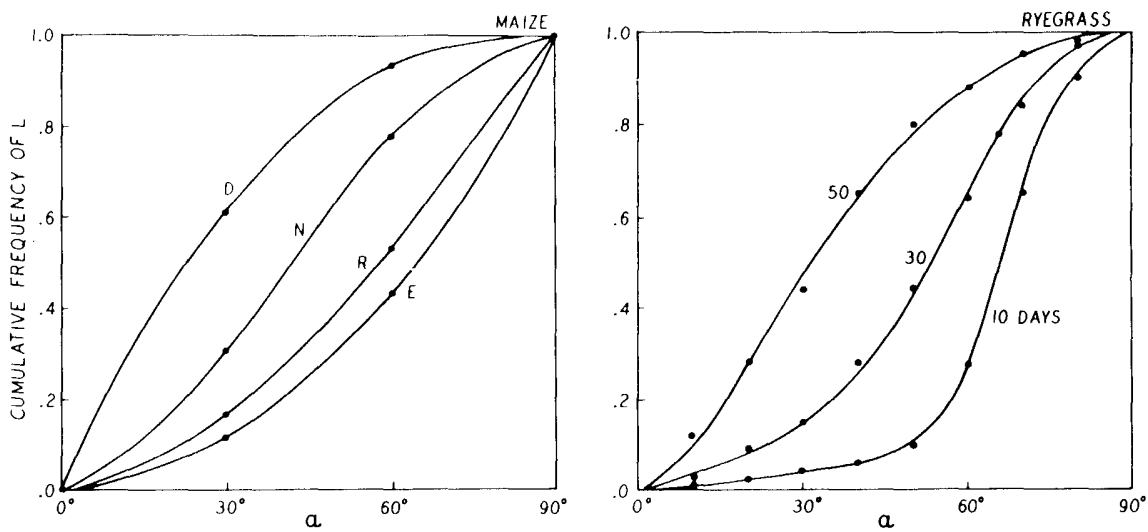

Fig. 3-3-Left: Cumulative frequency of leaf angles, for four maize communities. D-Davis, California (Loomis et al., 1968); N-Netherlands (after deWit, 1965); R-Russia (data of Nichiporovich, 1961); and E-Estonia (data of Ross and Nilson 1967b). Right: Cumulative frequency of leaf angles for ryegrass communities on June 10, after 10, 30, 50 days of growth (after deWit, 1965).

Ross and Nilson (1967a,b) made an excellent study on maize and horsebeans.

Figure 3-4 illustrates the two maize communities, horsebean (Vicia faba L.), and sugar beet (Beta vulgaris L.). The drawings for the Estonian work were derived by assuming that the vertical distributions of L per stratum given by Ross and Nilson (1967a; Table 1, col. 2, maize; and Table 5, col. 5, horsebean) are for the same communities for which they later give fractional distribution data for leaf angle

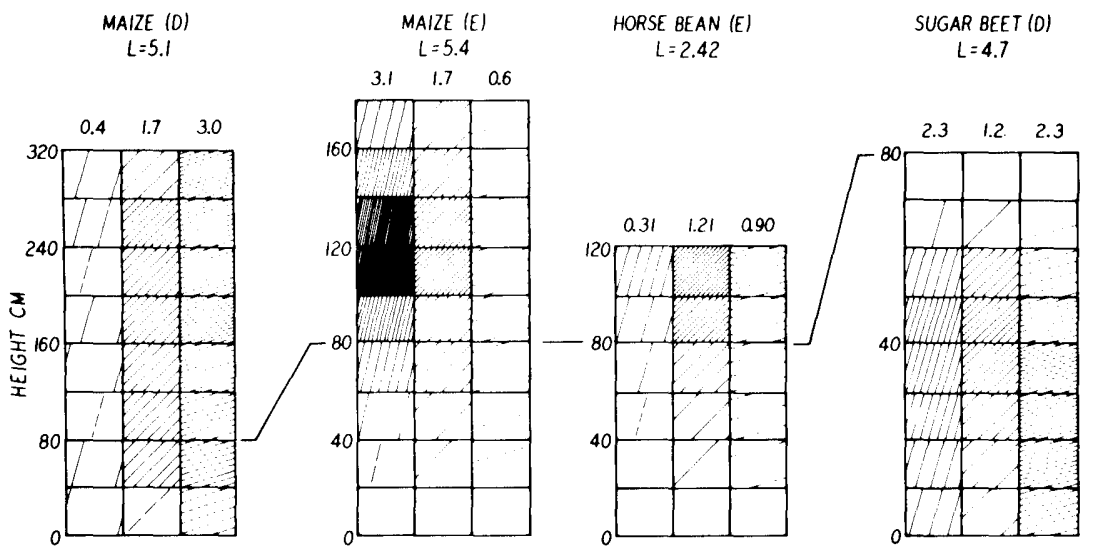

Fig. 3-4-Stratified leaf angle distribution for maize, horsebean, and sugar beet communities. Maize (D), Davis, California (Loomis et al., 1968); maize (E) and horsebean, Estonia (data of Ross and Nilson $1967 \mathrm{a}, \mathrm{b})$; the sugar beet was grown at Davis (previously unpublished data of Loomis et al.) The data are condensed and simplifjed from their original form. 
(1967b; Tables 3 and 6). The differences between the two maize communities is even more apparent in these graphs than in Fig. 3-3. Another interesting feature is the difference between the rossette sugar beet, with a high leaf density near the ground, and the caulescent horsebean which, like maize, has its greatest leaf density well above ground level. Since only a small number of cases are represented in these reports, broad generalizations are not possible. We can conclude, however, that leaf angle distributions may be quite different for various strata, and that a single mean angle for each stratum sometimes would be a poor representation of canopy morphology.

DeWit (1965, p. 13) argues that the additional work of stratified sampling is not justified because of the small effect which different leaf distribution functions have on photosynthesis. But simulation studies indicate differently. This is illustrated in Table 3-2 where production is simulated for two contrasting canopies with equal leaf angle distribution functions (considering each angle class occurs at the same frequency for the whole canopy). The canopy with horizontal leaves in the upper strata (clover) is less efficient at all values of $\mathrm{L}$ than the inverted canopy (grass), and the relative difference becomes greater as $\mathrm{L}$ increases. Thus, other factors being equal, stratified sampling may be essential if one wishes to compare the efficiency of various productive structures.

\section{G. Light Distribution Models}

The actual flux of light received by each individual leaf must be known in order to estimate its photosynthesis, a consequence of the curvilinear response of photosynthesis to increasing light flux (Fig. 3-5, left). Moreover Boysen-Jensen (1932) and others before him (see review by Anderson, 1964) pointed out that foliage angle affects not only the relative illumination of a fully exposed leaf, but also the projected shadow area of the leaf and thus the flux of light available to lower leaves. Another consequence of the curvilinear nature of photo-

Table :3-2-Simulated daily production rates with the Duncan model for three communities with $\bar{\alpha}=45^{\circ}$. Communities $B$ and $C$ have the same leaf

distribution functions but the vertical distribution of $\boldsymbol{a}$ has been inverted. All stands have 10 leaf layers each with 0.1 of the total L.

\begin{tabular}{|c|c|c|c|c|}
\hline \multirow[b]{2}{*}{ Stand } & \multirow[b]{2}{*}{ Description } & \multicolumn{3}{|c|}{$\begin{array}{c}\text { Production rate, } \\
\text { when } \mathrm{L}=\end{array}$} \\
\hline & & 2 & 4 & 8 \\
\hline & & \multicolumn{3}{|c|}{$\mathrm{g} \mathrm{m}^{-2}$ day $^{-1}$} \\
\hline A & $\alpha=45^{\circ}$ for each layer & 30 & 38 & 38 \\
\hline B & $\alpha=90^{\circ}$ for the top layer & & & \\
\hline \multirow{2}{*}{$\mathrm{C}$} & $\begin{array}{l}\text { decreasing to } 0^{\circ} \text { at the bottom } \\
\alpha=0^{\circ} \text { for the top layer }\end{array}$ & 32 & 41 & 47 \\
\hline & Increasing to $90^{\circ}$ at the bottom & 29 & 35 & 34 \\
\hline
\end{tabular}



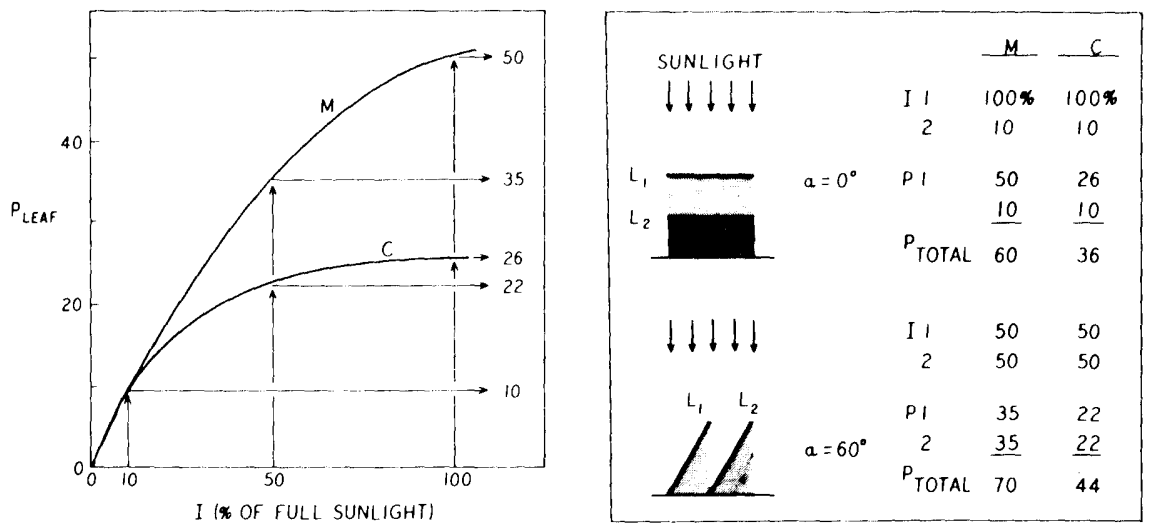

Fig. 3-5-Left: Leaf photosynthesis for maize (M) and clover (C) as a function of illumination. 'These species illustrate different degrees of light saturation in full sunlight. Right: Simple models and calculations of community photosynthesis for maize (M) and clover (C) with two leaf distributions of $\mathrm{L}=2$. With $a=0^{\circ}$, illumination (I) amounts to $100 \%$ and $10 \%$ of full sunlight. With $\alpha=60^{\circ}$, I amounts to $50 \%$ of full sunlight. $P_{1}$ and $P_{2}$ at the various illumination levels were obtained from Fig. 3-5, left as indieated by the arrows.

synthetic light response curves is that higher production and hence, more efficient light utilization is achieved by illuminating, many leaves at a modest level of light than by exposing a few leaves to full sun (Fig. 3-5, right).

Thus, a key problem is to relate the distribution of sun flecks and diffuse light within the community to the morphology of the community. In this way the light environment of each photosynthetic organ can be characterized. These considerations led to development of mathematical models which would predict light distribution within canopies. Monsi and Saeki (1953) and Kasanaga and Monsi (1954) developed expressions of the general form of equation (2) for homogeneously arranged leaves of uniform inclination $\alpha$, where the extinction coefficient, $K$, was a variable computed from geometrical considerations of $\alpha, \beta$ (the elevation angle of the light source), and L. $K$ was found to approach 1 for horizontal leaves (even exceeding 1.0 in nonrandom mosaic arrangements) and to decline as $\alpha$ increased.

Warren Wilson (1960) with Reeve has outlined a geometrical theory for the probability of contacting leaves of given leaf angle by an inclined point. Saeki (1963) and Anderson (1966a) showed the correspondence between this theory and that of Monsi and Saeki (1953). The point quadratprobabilities can be taken to represent the average shadow area $\mathrm{F}^{\prime}$ cast in the direction $\beta$, of a large number of leaves of area $F$. For $\alpha \leq \beta$,

$$
\left[\mathrm{F}^{\prime} / \mathrm{F}\right]_{\alpha, \beta}=\cos \alpha \sin \beta
$$


and for $\alpha>\beta$,

$$
\left[\mathrm{F}^{\prime} / \mathrm{F}\right]_{\alpha, \beta}=\sin \beta \cos \alpha\left[1+\frac{2}{\pi}\left(\tan \theta_{\mathrm{o}}-\theta_{\mathrm{O}}\right)\right]
$$

where $\theta_{0}$, expressed in radians, is the angle whose $\cos =\cot \alpha \tan \beta$. These expressions can be used to estimate the sunlit area of a foliage canopy by considering $\beta$, the point quadrat angle of elevation, to be the solar angle. If leaves are randomly arranged in horizontal strata, then the Poisson distribution may be employed (Duncan et al., 1967) and

$$
\mathrm{I}=\mathrm{I}_{\mathrm{O}} \exp \left(-\mathrm{L}\left[\mathrm{F}^{\prime} / \mathrm{F}\right]_{\alpha, \beta} / \sin \beta\right)=\mathrm{I}_{\mathrm{o}} \exp (-\mathrm{KL})
$$

where I and $I_{0}$ are expressed as horizontal areas illuminated by direct sun and $\mathrm{K}$ is the extinction coefficient.

This function for $\mathrm{K}$ is plotted against $\alpha$ and $\beta$ by Anderson (1966a) and Loomis et al. (1967); K = 1 when $\alpha=0$, and is a constant as long as $\alpha \leq \beta$. This means that for many canopies, values of $\mathrm{K}$, measured when most of the light comes from high elevations, can be used in characterize the canopy. As we have seen, a random distribution as assumed here approximates many real communities and serves as a benchmark with which to compare over-and under-dispersed foliages.

In Fig. 3-6 are illustrated the variations in sunlit foliage area resulting from application of equation (5) to a foliage providing complete cover (Warren Wilson, 1967). Such area is greatest when $\alpha$ and $\beta$ are both large; but for small values of $\beta$ the area is greatest for more horizontal leaves. Actual illumination of each unit of area will vary according to the sine of the angle of incidence. Interestingly, as long as $\alpha \leq \beta$, the sunlit area is independent of $\beta$, being equal to $\sec \alpha$. For example, with $\alpha=0$ sunlit leaf area equals 1.0 .

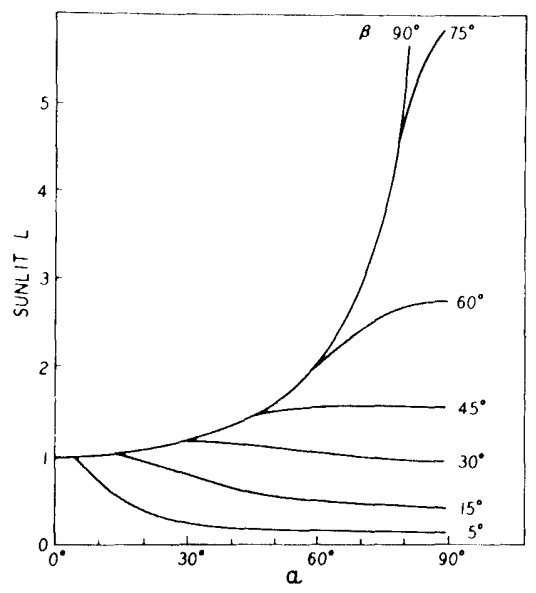

Fig. 3-6-Sunlit (skylight not considered) foliage area in canopies with randomly displayed leaves of various inclinations. $\beta$ is solar elevation. (After Warren Wilson, 1967.) 
The equations shown for direct sun also suffice to describe the penetration of diffuse light from a particular point in the sky. Hanau's equations (Duncan ot ai., 1967) offer a more complete solution, however. and permit calculation of illumination on either or both surfaces of a leaf of any angle from any zone of a hemispherical sky. (In most models it is assumed that illumination of the lower surface of a leaf is equally effertive in photosynthesis to illumination of the upper surface). The relative brightness of sun and total sky can be obtained fairly readily, but there is little information on the brightness of different regions of the sky under various meteorological conditions. Anderson (1966a) discusses the Moon and Spencer's Standard Overcast Sky which is azimuthally uniform but brightest at the zenith, while Duncan et al. (1967) like Monsi and Saeki (1953) have used a uniform sky. We are now working on approximating any sky comprised of varying proportions or clear, cloudy, and smoggy conditions. Preliminary results indicate that productivity levels and optimum canopy structure differ appreciably for various sky conditions.

Most models have for simplicity ignored the contributions of diffuse light originating from reflections and transmission within the canopy. This light can be important to production as has been indicated by computer simulation (Duncan et al., 1967).

As an alternative to the geometrical solution given in equation (5), solutions may be based on measured light "transmission" or "penetration" coefficients. As an example, the following function was developed by Kasanaga and Monsi (1954) for illumination penetrating the Nth layer of horizontal leaves:

$$
\mathrm{I}=\mathrm{I}_{\mathrm{O}} \mathrm{M}^{\mathrm{N}}
$$

where $\mathrm{M}=1-(1-\mathrm{T}) \mathrm{L}$, and $\mathrm{T}$ is the light transmission coefficient. By coupling these expressions with a function for the photosynthesis response to light, they made production calculations which agreed reasonably well with measured values.

Monteith (1965) extended this approach to deal with inclined leaves by introducing a parameter s equal to the fraction of light which passes a unit leaf layer without interception. Thus, $s$ is 0 for a continuous sheet of foliage normal to a distant point-light source and 1.0 for leaves parallel to the light rays. The resulting equation for illumination penetrating the Nth layer is

$$
\left.\mathrm{I}=\mathrm{I}_{0} \mid \mathrm{s}+(1-\mathrm{s}) \mathrm{T}\right\}^{\mathrm{N}}
$$

If each layer consists of a unit L, (i.e., $\mathrm{N}=\mathrm{L}$ ) then

$$
\mathrm{I}=\mathrm{I}_{\mathrm{O}} \exp \{\mathrm{L} \ln [\mathrm{s}+(1-\mathrm{s}) \mathrm{T}]\}
$$

and by analogy to equation (2), the extinction coefficient is 


$$
\mathrm{K}=-\ln [\mathrm{S}+(1-\mathrm{S}) \mathrm{T}]
$$

Taking $\mathrm{s}=0.7$ for grass and 0.4 for prostrate-leaved plants, Monteith calculated several light distributions that were applied with appropriate photosynthetic functions to give a reasonable fit to measured production curves. Variations in s have a large effect on calculated productivity. Warren Wilson (1967) points out, that s taken as a constant for a given canopy implies that the source of all light was from the zenith, with $\mathrm{I}_{O}$ varying to stimulate changes in solar inclination. We should note that the empirical $s$ integrates all variations in leaf distribution. To answer questions about canopy morphology and yield, a model must simulate s from the leaf distribution. Thus, this approach is much less useful in its application than is Monsi and Saeki's original geometrical solution for inclined leaves.

Model construction has reached a point where many of the parameters which affect light distribution within canopies can be considered together. Such models give discrete solutions and thus for optimization, the parameters must be varied systematically and the entire simulation rerun repeatedly. Until the sophistication of the models is improved and until they can be coupled with microclimate models, it is difficult to justify efforts to deduce an "ideal" foliage for each crop at each latitude and date. However, specific solutions to simple comparisons can be reached. The vertical distribution of leaves, and within each stratum, the distribution within various angle classes are revealed to be of critical importance.

Thus far, models for evaluating nonrandom (contagious or mosaic) distributions within layers, or for assigning leaf elements to individual plants (for studies on competition), are still in their infancy. These features are obviously of considerable importance in real communities. Ultimately, we can hope to simulate row and spacing effects, interspecific and (as a basis for examining the course of evolution) intraspecific competition.

\section{H. Azimuthal Orientations}

Ross and Nilson (1967b) gave attention to azimuthal orientation of leaves by employing a device to determine to which of 48 sky zones (each $15^{\circ}$ elevation by $45^{\circ}$ azimuth) the normal to a portion of a leaf pointed. When planted in rows (direction unspecified), maize had a significant azimuthal tendency toward east-west orientation of leaves; horsebeans had little azimuthal orientation. The observation with maize is of special interest because of Peters' (1961) attempts at seed-oriented plantings of this crop to provide a strongly mosaic leaf arrangement for maximizing light interception.

Nichiporovich (1961) and Loomis et al. (1968) failed to observe this east-west tendency in their maize communities, but Udagawa et al. (1968) found maize leaves to be somewhat elongated in the direction of their northeast-southwest rows. Apparently a strong azimuthal orientation is an inherited characteristic in some crops. We have observed strong east-west orientation of leaves by a few varieties of both maize 


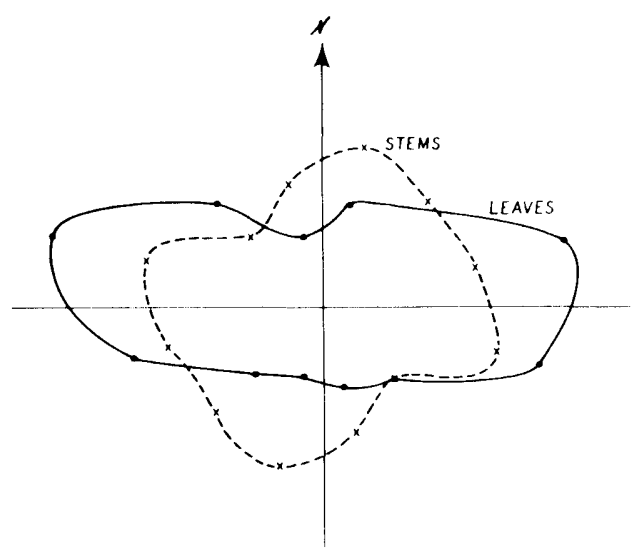

Fig. 3-7-Azimuthal distribution of maize leaves and stems. The mean of leaves $4,5,9$, and 10 from first foliage leaf, and the stem axis at ground level are plotted (previously unpublished data of Loomis et al.).

and sorghum regardless of row direction (Fig. 3-7). Our tentative suggestion is that the effect is related to solar path as much as to row direction and plant density. Solar orientations of leaves are not uncommon. Heliotropic movements by sunflower and the occurrence of "compass" plants such as Silphium are well known; but the potential of these traits for affecting productivity remains to be studied.

\section{Nonleaf Structures}

Light interception by nonphotosynthetic tissues is an additional feature of canopy morphology. In woodlands, the importance of trunks and branches to the light environment of understory plants is apparent; but the role of stems and branches has been felt to be of less importance in herbaceous communities and is generally ignored. While stems are the most obvious component of the morphology, it also may be useful to consider other tissues. El-Sharkawy and Hesketh (1965) found that subtraction of nongreen vein areas from leaves of certain species brought their photosynthetic rates per unit area more closely into line with those of other species. On a different scale, light interception by flower structures may be appreciable. As an example, Duncan et al. (1967) found that about $9 \%$ of the daily isolation may be intercepted by tassels of a maize crop at commercial densities $(50,000$ plants $/ \mathrm{ha}$ ) and $18 \%$ may be intercepted at twice that density.

With herbaceous plants, stem (and with grasses the sheaths which enclose them), petioles and inflorescence parts may contain appreciable chlorophyll, and thus represent productive as well as light intercepting structures. While the role of cereal awns and glumes in photosynthesis has been well documented, little is known about the photosynthetic rates associated with most other such organs. Their relative abundance is not necessarily small. In maize (Williams et al., 1965a), the surface areas of culms with sheaths, treated as elliptical cylinders, varied 
from 9 to $18 \%$ of the total green surface with advancing stages of growth, but varied little as population density was increased from 6,700 to 700,000 plants/ha. Ross and Nilson (1967a) reported the fraction of $L$ found as Les (the accumulated surface area of stems treated as cylinders) varied from 5 to $13 \%$ in maize, was about $9 \%$ in horsebean, and increased to as much as 40 or $50 \%$ in wheat (Triticum vulgare L.), white clover, and bromegrass (Bromus spp.).

While stem area may be an appreciable part of the total in herbaceous communities, a compensating feature is that this area is usually distributed pyramidally, with the bulk of the area in the lower strata; hence it does not interfere with interception by leaves (Warren Wilson, 1965; Williams et al., 1965a). The reverse is true for many grasses.

If we exclude from the canopy morphology any nonleaf structures which occur in the heavily shaded regions of the canopy, some of the leaf area itself might be considered as nonleaf. Our general conclusion is that more attention needs to be given to nonleaf components of canopies.

\section{RELATION OF CANOPY MORPHOLOGY TO PRODUCTION}

Establishing relationships between canopy morphology and yield presents a number of difficulties. Agriculturalists have been principally concerned with economic yield, and variation in parameters affecting partitioning of production becomes confounded with variations in production rate. Translocation, respiration, and hormonal controls on partitioning, as discussed in later chapters, determine the correlation between primary productivity and economic yield. Time dependency also causes problems in interpreting integrative characters such as grain yield. It is well to recall the importance of rate of leaf area development and of leaf area duration (Watson, 1952; Nichiporovich, 1966). The shorter the season, the more dependent crop yield will be upon the rate at which full cover is reached, and on the efficiency of the canopy at small values of $\mathrm{L}$. Thus, a short-season crop such as cantaloup (Cucumis melo L. var. reticulatus Nand.) develops only a small leaf area but one containing highly dispersed horizontal leaves.

Beyond these factors, canopy morphology affects more than just visible light distribution among leaves, and photosynthesis. The patterns of leaf distribution influence air circulation, canopy roughness and hence the efficiency of eddy turbulence. These factors in turn affect $\mathrm{CO}_{2}, \mathrm{H}_{2} \mathrm{O}$ vapor, and heat transfer. Since leaf disposition also. determines the receipt and loss of short and long wave radiation, canopy architecture in effect determines microclimate. Modeling efforts are being made on each of these aspects, and before long canopy architecture will be assessed on a much broader basis than on just light distribution.

\section{A. Simulations of Crop Productivity}

DeWit (1965), Monteith (1965), and Duncan et al. (1967) all reached similar basic conclusions, through simulations, regarding the influence of variations in $\alpha$ and $\mathrm{L}$. That is, when $\mathrm{L}$ is small, horizontal leaves 

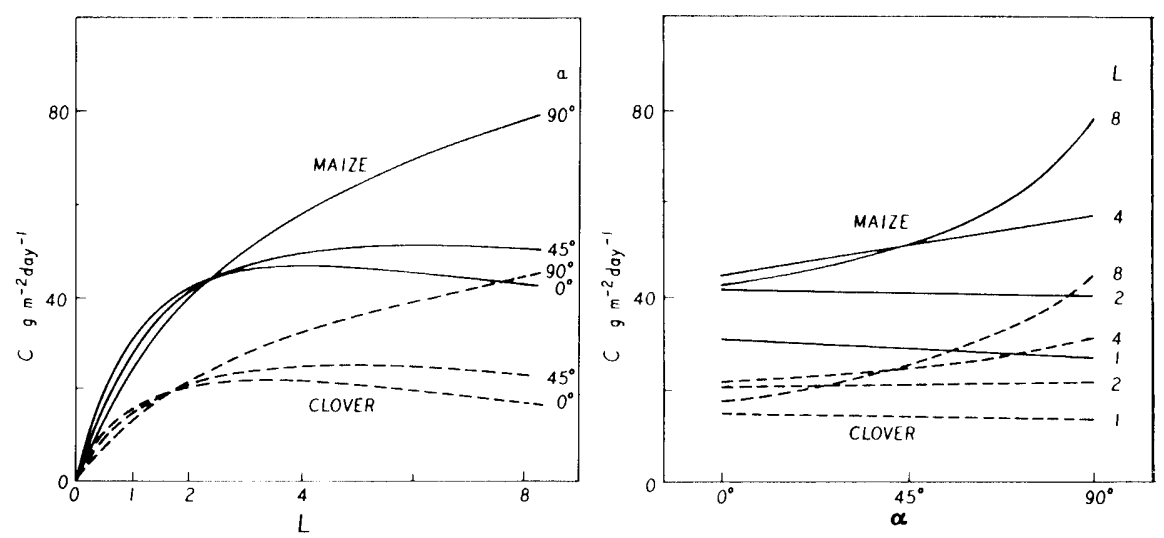

Fig. 3-8-Simulations of daily crop growth rates (C) for maize and clover communities of various $L$ and a combinations. Solar and skylight data of $38^{\circ} \mathrm{N}$. latitude for July 1. Left: $C$ as a function of $L$ for various values of $\alpha$. Right: The same data plotted with $\mathrm{C}$ as a function of $a$ for various values of $\mathrm{L}$.

are advantageous; at large values of $L$, more erect leaves give greater production. Further, optimal L, or at least a pronounced optimum, is not evident providing the lower leaves adapt physiologically to the shade environment. The Duncan model is the most flexible with regard to input and the most rigorous as to theory. This model was used to compute the production rates illustrated in Fig. 3-8. Photosynthesis rate is computed for each hour of the day and then summed and corrected for respiration to give an estimate of daily production. With $\beta$ max for the day at $74^{\circ}$, inclined leaves show a marked advantage only when L exceeds 2 to 4 , and erect leaves only when L approaches high values of 8 or more. This was true for the photosynthetic functions of both maize and clover (Fig. 3-5, left; i.e., whether or not the individual leaves light saturated with less than full sun), but crossover points and daily production rates are quite different. Also, leaf photosynthetic rate is revealed as a powerful determinant of crop growth rate.

The influences of varying sky conditions, latitude, physiological functions and leaf optical properties have been explored briefly with this model. Figure 3-8 serves to summarize much of what can now be said about an ideal foliage for light interception in latitudes up to 50 or $60^{\circ}$. Azimuthal distributions, nonrandom patterns, including those of row effects and genotypic mixtures, could be considered and remain to be examined. One point made clear from Fig. 3-8 is that simulations are essential to the proper design and interpretation of field experiments on patterns with leaves.

\section{B. Some Experimental Results}

The hypothesis that erect leaves should confer tolerance to crowding is widely accepted and several tests of its validity have been attempted. Pendleton et al. (1968) developed genetic isolines of maize 
with "normal" and "upright" leaves. These were compared for grain production with a moderately high density of plants $\left(59,000\right.$ plants ha $\left.{ }^{-1}\right)$ with $\mathrm{L}$ reaching 4.0. Unfortunately, the normal variety was intolerant of high densities. Thus while the "upright"line yielded $41 \%$ more grain, a large part of this difference was related to differences in numbers of barren plants, a circumstance more related to carbohydrate status of individual plants at silking than to crop growth rate. A second phase of the experiment demonstrated a striking influence of leaf angle. Leaves of a planophile variety were positioned upright by mechanical means. With $\mathrm{L}=4.1$, the normal display intercepted $99 \%$ of the incident light near noon as compared to $90 \%$ intercepted when leaves above the ear were upright, and $84 \%$ with all leaves upright. Grain yields were $10,700,12,200$, and $11,400 \mathrm{~kg} \mathrm{ha}^{-1}$, respectively.

At $\mathrm{L}=4$, simulation models with physiological functions for maize predict only a small advantage in primary productivity from upright as compared to horizontal leaves (Fig. 3-8). Considering only the data on light interception, and remembering that $\mathrm{C}$ is usually found to vary directly with percent cover, we would expect that $\mathrm{C}$ would have declined with increasing proportions of upright leaves. Thus, it appears that the grain yield advantage with upright leaves was not the result of greater C. Rather, as Pendleton et al. suggest, greater illumination of leaves adjacent to the developing ears may have been the cause of a greater proportion of the assimilate being accumulated by the grain.

In Ontario, Stoskopf (1967) compared grain yields from "droopy" and "upright" winter wheats. The upright selentions from New York may have been slightly less suited to the environment than the well adapted "droopy" control, and gave lower yields. However, the yield increase obtained from narrow as compared with wide row spacings was greatest with the upright types. Data on maturity dates, L, and biomass were not given. Here again it is impossible to draw very general conclusions from the data. Did the communities attain $L$ values at which erect leaves might increase $\mathrm{C}$, or, indeed, with this latitude, time of year, and sky conditions, would erect leaves confer an advantage at any $L$ ? The weight of the Guelph researchers' experience points towards affirmative answers.

Watson and Witts (1959) compared an erect-leaved sugar beet with several prostrate-leaved wild progenitors. E for the sugar beet declined less as $L$ increased, indicating perhaps that the increase in mutual shading was least with erect leaves. In these experiments, as Monteith (1965) points out, L was small (2 to 3 ) and the real advantage of the sugar beet may have been due principally to greater dispersion of leaves (longer petioles and hence greater percent light interception than with the wild beet?). At $\mathrm{L}=2$ to 3 , the simulations illustrated in Fig. 3-8 predict a slight advantage for horizontal leaves.

These experiments are among the better efforts, but they illustrate some of the problems in establishing cause and effect relations between canopy morphology and agronomic yield. Many more careful and detailed experiments are needed. We need to distinguish the role of physiological processes (e.g., partitioning efficiency, photosynthetic capability, and respiration) from advantages conferred by changes in the 
patterns among leaves. The definition of an "ideal" foliage canopy depends upon our establishing guiding principles about the interactions of these factors within particular environments. Obviously, we cannot explore each point of possible significance adequately or quickly enough by experiments with genetic isolines or mechanical manipulations. The modeling efforts described earlier assume an essential role since many aspects of production processes can now be investigated through simulations.

\section{ACKNOWLEDGMENTS}

Portions of the original data reported here were obtained through research supported by the National Science Foundation (GB 4192) and by the California sugar beet industry.

\section{LITERATURE CITED}

Anderson, Margaret C. 1964. Light relations of terrestrial plant communities and their measurement. Biol. Rev. 39:425-486.

Anderson, M. C. 1966a. Some problems in the characterization of the light climate in plant communities. In: R. Bainbridge, G. C. Lvans, and O. Rackham (ed.). Light as an ecological factor. Symp. Brit. Ecol. Soc. 6:77-90. John Wiley, New York.

Anderson, Margaret C. 1966b. Stand structure and light penetration. 11. A theoretical analysis. J. Appl. keol. :3:4t-54.

Baker, D. N., and R. F. Meyer. 1966. Influence of stand geometry on light intereeption and net photosynthesis in cotton. Crop sci. 6:15-19.

Björkman, O., and P. Iolmgren. 1963. Adaptability of the photosynthetic apparatus to light intensity in ecotypes from exposed and shaded habitats. Physiol. Plant. 16:889-914.

Black, J. N. 1963. The interrelationship of solar radiation and leaf area index in determining the rate of dry matter production of swards of subterranean clover ('I'rifolium subterrancan L.). Aust. J. Agr. Res. 14:20-38.

Blackman, G. E. 1962. The limit of plant productivity. Ann. Rep. East Malling Res. Sta. for 1961 . p. 39-50.

Boysen Jensen, P. 1932. Dic Stoffproduktion der Pfanzen. G. Fiseher, Jena.

Bray, J. R. 1960. The chIorophyll content of some native and managed plant communities in central Minnesota. Can. J. Bot. 38:313-3333.

Brougham, R. W. 1956 . Effect of intensity of defoliation on regrowth of pasture. Aust. J. Agr. Sci. 7:377-387.

Brougham, R. W. 1960. The relationship between the critical leaf area, total chlorophyll content, and maximum growth-rate of some pasture and crop plants. Ann. Bot. 24:463-474.

DeWit, C. T. 1965. Photosynthesis of leaf canopies. Agr. Res. Rep. no. 663, Central Agr. I’ubl. Doc., Wageningen.

Duncan, W. G., W. A. Williams, and R. S. Loomis. 1967. Tassels and the productivity of maize. Crop Sei. 7:37-39.

Duncan, W. G., R. S. Loomis, W. A. Williams, and R. Hanau. 1967. A model for simulating photosynthesis in plant communities. Hilgardia 38:181-205.

El-Sharkawy, M., and J. Hesketh. 1965. Photosynthesis among species in relation characteristics of leaf anatomy and $\mathrm{CO}_{2}$ diffusion resistances. Crop Sci. $5: 517-521$. 
Evans, G. C. 1966. Model and measurement in the study of woodland light. In: R. Bainbridge, G. C. Evans and O. Rackham (eds.). Light as an ecological factor. Symp. British Ecol. Soc. 6:53-76. John Wiley, New York.

Gabrielsen, E. K. 1948. Elfects of different chlorophyll concentrations on photosynthesis in foliage.leaves. Physiol. Plant. 1:5-37.

Goldman, C. R., and R. C. Carter. 1965. An investigation by rapid carbon-14 bioassay of factors affecting the cultural entrophication of Lake Tahoe, California-Nevada. J. Water Poll. Cont. Fed. 37:1044-1059.

Greig-Smith, P. 1964. Quantitative plant ecology. Butterworths, Washington, D.C.

Heinicke, D. R. 1963. The microclimate of fruit trees: II. Foliage and light distribution patterns in apple treos. Amer. Soc. Hort. Sci., Proc. 83:1-11.

Jahnke, S., and D. B. Lawrence. 1965. Influence of photosynthetic erown structure on potential productivity of vegetation, based primarily on mathematical models. Ecology $46: 319-326$.

Kasanaga, H., and M. Monsi. 1954. On the light-transmission of leaves, and its meaning for the production of matter in plant communities. Jap. J. Bot. 14: $304-324$.

Kershaw, K. A. 1957. The use of cover and frequency in the detection of pattern in plant communitics. Ecology 38:291-299.

Loomis, R. S., W. A. Williams and W. G. Duncan. 1967. Community architectecture and the productivity of terrestrial plant communities, p. 291-308. In: A. San Pietro, F. A. Greer, and T. J. Army (ed.) Harvesting the sun. Academic Press, New York.

Loomis, R. S., W. A. Williams, W. G. Duncan, A. Dovrat, and F. Nunez A. 1968. Quantitative descriptions of loliage display and light absorption in lield communities of corn plants. Crop Sci. 8:352-356.

Monsi, M., and T. Sacki. 1953. Ujber den Lichtfaktor in den P'flanzengesellshaften und seine Bedeutung für die Stoffproduktion. Jap. J. Bot. 14:22-52.

Monsi, M. 1968. Mathematical models of plant communities, p. 131-149. In F. E. Eckardt (ed.) Functioning of terrestrial ecosystems at the primary production level. UNESCO, Paris.

Monteith, J. L. 1965. Light distribution and photosynthesis in field crops. Ann. Bot., N.S. $29: 17-37$.

Nichiporovich, $\Lambda$. A. 1966. Aims of rescarch on the photosynthesis of plants as a factor in productivity. In A. A. Nichiporovich (ed.) Photosynthesis of productive systems. Transl. edition. Israel Prog. Sci. Transl., Jerusalem.

Okubo, T., H. Oizumi, M. Hoshino and S. Nishimura. 1968. Chlorophyll amount for analysis of matter production in forage crops, p. 43-46. In Photosynthesis and utilization of solax energy - Level III experiments. Japanese IBP/PP Group. Tokyo.

Pendleton, J. W., G. E. Smith, S. R. Winter, and T. J. Johnston. 1968. Field investigations of the relationship of leaf angle in corn (Zea mays L.) to grain yield and apparent photosynthesis. Agron. J. 60:422-424.

Peters, D. B. 1961. Water use by field crops. Plant Food Rev. 7(1):14.

Philip, J. R. 1965. The distribution of foliage density with foliage angle estimated from inclined point quadrate observations. Austral. J. Bot. 13:357-366.

Ross, Y. K., and T. Nilson. 1967a. The vertical distribution of biomass in crop stands. In A. A. Nichoporovich (ed.) Photosynthesis of productive systems. Translated edition. Israel Prog. Sei. Trans., Jerusalem. pp. 86-95.

Ross, Y. K., and 'T'. Nilson. 1967b. The spatial orientation of leaves in crop stands and its determination. In $\Lambda$. A. Nichiporovich (ed.) Photosynthesis of productive systems. Translated edition. Israel Prog. Sci. Trans., Jerusalem. p. $75-85$.

Sacki, T. 1963. Light relations in plant communities, p. 79-94. In L. T. Evans (ed.) Environmental control of plant growth. Academic Press, New York. 
Santhirasegaram, K., and J. N. Black. 1968. The distribution of leaf area and light intensity within wheat crops differing in row direction, row spacing, and rate of sowing; a contribution of the study of undersowing pasture with cereals. J. Brit. Grassland Soc. 23:1-12.

Shaw, R. E., and C. R. Weber. 1967. Effeets of canopy arrangement on light interception and yield of soybeans. Agron. J. 59:155-159.

Shibles, R. M., and C. R. Weber. 1965. Leaf area, solar radiation intereeption and dry matter production by soybeans. Crop Sci. 5:575-577.

Shibles, R. M., and C. R. Weber. 1966. Intereeption of solar radiation and dry matter production by various soybean planting patterns. Crop Sci. 6:55-59.

Steeman Niclsen, E. 1957. The chlorophyll content and the light utilization in communities of plankton algae and terrestrial higher plants. Physiol. Plant. $10: 1009-1021$.

Stern, W. R., and C. M. Donald 1962. The influenec of leaf area and radiation on the growth of elover in swards. Austral. J. Agr. Res. 13:615-623.

Stoskopf, N. C. 1967. Yicld performanec of upright-leaved selections of winter wheat in narrow row spacing. Can. J. Plant Sci. 47:597-601.

Szeich, G., J. L. Monteith, and J. M. Dos Santos. 1964. Tube solarimeter to measure radiation among plants. J. Appl. Ecol. 1:169-174.

Takeda, T. 1961. Studies on the photosynthesis and production of dry matter in the community of rice plants. Jap. J. Bot. 17:403-437.

Talling, J. F. 1961. Photosynthesis under natural conditions. Ann. Rev. Plant Physiol. 12:133-154.

Udagawa, T., Z. Uchijima, T. Horie, and K. Kobayashi. 1968. Canopy structure of the corn plant, p. 20-24. In Photosynthesis and utilization of solar energy Level III experiments. Jap. $\overline{\mathrm{IB}} \mathrm{P} / \mathrm{PP}$ Group. Tokyo.

Verhagen, A. M. W., J. H. Wilson, and E. J. Britten. 1963. Plant production in relation to foliage illumination. Ann. Bot. N.S. 27:627-640.

Warren Wilson, J. 1959. Analysis of the spatial distribution of foliage by twodimensional point quadrats. New Phytol. 58:92-101.

Warren Wilson, J. 1960. Inclined point quadrats. New Phytol. 59:1-8.

Warren Wilson, d. 1961. Influence of spatial arrangement of foliage area on light interception and pasture growth. Proc. 8th Int. Grassl. Cong. pp. 275279.

Warren Wilson, J. 1965. Stand structure and light penetration. I. Analysis by point quadrats. J. appl. Ecol. 2:383-390.

Warren Wilson, J. 1967. Stand structure and light penetration. III. Sunlit foliage area. J. appl. Ecol. 4:159-165.

Watson, D. J. 1947. Comparative physiological studies on the growth of field crops. I. Variation in net assimilation rate and leaf area between specics, and within and between years. Ann. Bot. N.S. 11:41-76.

Watson, D. J. 1952. The physiological basis of variation in yield. Adv. Agron. $4: 101-145$.

Watson, D. J. 1958. The dependenee of net assimilation rate on leaf area index. Ann. Bot. N.S. $22: 37-55$.

Watson, D. J., and K. J. Witts. 1959. The net assimilation rates of wild and cultivated beets. Ann. Bot. N.S. 23:431-439.

Williams, W. A., R. S. Loomis, and C. R. Lepley. 1965a. Vegetative growth of corn as affected by population density: I. Productivity in relation to interception of solar radiation. Crop Sci. 5:211-215.

Williams, W. A., R. S. Loomis, and C. R. Lepley. 1965b. Vegetative growth of corn as affected by population density. II. Components of growth, net assimilation ratc, and leaf area index. Crop Sci. 5:215-219. 


\section{3 ...DISCUSSION}

DONALD N. BAKER

Agricultural Research Service, USDA

Boll Weevil Research Laboratory

State College, Mississippi

Little needs to be added to Drs. Loomis' and Williams' presentation. They have done a very creditable job of reviewing a complex subject. There are, however, two related questions pertaining directly to these models of photosynthesis by plant communities which merit consideration. The first concerns experimental verification and the second deals with the matter of systems applications.

Evidently, not every one who is capable of making contributions in the development of these models is equipped or has the time to verify them experimentally by making short term measurements of photosynthesis in intact stands. Such measurements are not by any means impossible, but they are not easy to do either. So, the question is, would such an effort be justified, is it necessary, or can we be confident of the essential correctness and completeness of our models as they are now?

These models are designed to account for the effects of leaf angle, sun angle, etc., on photosynthesis by the stand. Two physical factors are handled very well, stand geometry and the angle of incidence of the radiation. Such a model then, should provide the diurnal variation of stand photosynthesis by the minute. What concerns me is that most efforts at experimental verification have been done by dry weight measurements over days. This gets one into the technical problem of plant sampling, but it also requires an accounting for day and night respiration by the crop. Plant sampling and the measurement of dry weight increases over several days time would seem to be a rather crude way of testing a model designed to estimate increments of carbon assimilation over minutes.

Concerning the application of these models, many agronomists are interested in simulating crop growth and development, using classical systems engineering methods. Stand photosynthesis is one of the basic subsystems about which we have to be concerned. Recently Dr. Hesketh and $I$ have been incorporating our photosynthesis and respiration data into a model for the study of potential fruit development. This is a study of the distribution of photosynthesis. Without going into the derivation, I can give the result as follows:

$$
\frac{\mathrm{dW}}{\mathrm{dt}}=\mathrm{P}-\mathrm{RW}
$$


where $\mathrm{W}$ is fruit weight in $\mathrm{mg} / \mathrm{dm}^{2}$ ground area, $\mathrm{t}$ is time in days, $\mathrm{P}$ is gross photosynthate in $\mathrm{mg} / \mathrm{dm}^{2}$ ground area/day, and $\mathrm{R}$ is the respiration rate in $\mathrm{mg} / \mathrm{g}$ dry wt/day. We are defining $\mathrm{P}$ as follows,

$$
\mathrm{P}=\mathrm{P}^{\prime}-\mathrm{R}_{\mathrm{Vn}},
$$

where $\mathrm{P}^{\prime}$ and $\mathrm{R}_{\mathrm{Vn}}$ are daytime net carbon exchange and night respiration loss by the vegetative tissue. $\mathrm{R}$ is the day plus night fruit respiration. $R_{\mathrm{Vn}}$ equals slightly less than $10 \%$ of a typical day's net photosynthesis $\left(\mathrm{P}^{\prime}\right)$ in cotton, and total daily $(24 \mathrm{hr}$ ) vegetative respiration equals $28 \%$ of P. Equation (1) applies to a determinate crop but for cotton it had to be modified as follows:

$$
\frac{d W}{d t}=P-R W+P\{1-\exp [-R(t-55)]\}
$$

where 55 days are required to mature a fruit. We've used experimental respiration and photosynthesis data to obtain an iterative solution to this expression. The result was a time course for the development of a theoretically possible fruit load for the 1966 growing season, and it was, to us, amazingly similar to behavior to the real system. It also gave us an estimate of the theoretical maximum yield.

This estimate of potential yield is based on carbohydrate supply. We've also obtained an estimate of potential yield from another system of equations based on carbohydrate demands by the fruit. The problem there is stated as follows:

$$
\frac{\mathrm{dC}}{\mathrm{dt}}=\frac{\mathrm{dW}}{\mathrm{dt}}+\mathrm{RW}
$$

where all symbols are defined as above except $\mathrm{C}$ which represents the carbohydrate need. Integration over time yields a total carbohydrate requirement and a final fruit weight. The conversion ratio obtained from these values, then, multiplied by the supply of photosynthete gives an estimate of yield. In this connection, we have found that $44 \%$ of the fruit carbohydrate requirement is for respiration. I would note in passing that this potential yield estimate is somewhat more precise in that it accounts for changes in the respiration rate of the fruit as a function of time.

Both of these approaches depend on an accurate estimate of the rate of photosynthesis. We have been using experimental data. This is satisfactory for some purposes, but the claim is made (and in a sense I think it is justified) that our present approach is not general enough. So, we need to move toward the application of an organization of "fundamental" relations. 


\title{
$3 \ldots$ DISCUSSION
}

\author{
J. W. TANNER
}

University of Guelph

Guelph, Ontario, Canada

Actual experimental data illustrating the importance of plant morphology to plant yield is difficult to find. I would like to cite some data and relate some observations which I feel are relevant to the discussion. C.J. Gardener, formerly a graduate student at Guelph, selected three high yielding barley varieties (Hordeum vulgare L.) and three low yielding barley varieties to determine, if possible, the physiologic reasons for their yield differences. It became apparent very early in the study that morphology was one of the major effects as the three high yielding varieties had narrow, upright leaves while the three low yielding varieties had wide dropping leaves. (These were relative but obvious differences.)

The higher yielding (upright) varieties showed slower initial growth rates, required a longer period before reaching $95 \%$ light interception, but had higher crop growth rates (C) subsequent to $95 \%$ light interception. The higher yielding varieties also exhibited a better distribution of light within the canopy.

Further, a comparison of the 1964 and 1965 data indicated that when the LAI's were high the more upright types showed higher $C$ values; when the LAI's were low the upright and drooping had almost identical $C$ values (Table 3D-1). This experimental data supports the theoretical prediction derived from Duncan's model (Duncan, 1967).

With this study in mind we proceeded to rank the material in the wheat (Triticum aestivum L.), oat (Avena sativa L.), and barley nurseries for yield, using only the attributes leaf angle and width as selection criteria. Approximately 300 varieties and lines were evaluated as high, medium, or low yielders. When these visual evaluations were checked with performance, it was shown that this method properly catagorized all of the 50 high-yielding strains except two. Twenty other varieties, classed as high-yielding by this visual method, did not fall into this category. The results of this visual evaluation indicated that for Ontario conditions these two leaf characteristics could provide useful criteria in selection for yield.

Further observations (Table 3D-2) of upright leaf types in variety trials proved to be equally enlightening. At one location where weeds were controlled chemically, a short wheat strain with extreme upright leaves yielded equal to the check varieties. At another location, where no herbicide treatment was used the strain was greatly reduced in yield. Weed growth between the rows was markedly more profuse than in the floppy-leaf types. A tall, leafy variety, developed at this latter location, 
Table 3D-1-Relationship between LAI and C (crop growth rate) for erectophile and planophile barley plants

\begin{tabular}{|c|c|c|c|c|}
\hline \multirow[b]{2}{*}{ Year* } & \multicolumn{2}{|c|}{ I A AI } & \multirow{2}{*}{$\frac{\mathrm{C}, \mathrm{g} \mathrm{m}^{-2}}{\text { Erectophile }}$} & \multirow{2}{*}{$\frac{\text { day }^{-1}}{\text { Planophile }}$} \\
\hline & Erectophile & Planophile & & \\
\hline 1964 & 93 & 9.5 & 306 & 25.7 \\
\hline 1965 & 3.2 & 3.5 & 23.6 & 23.9 \\
\hline
\end{tabular}

* 1964 normal moisture, above normal temperature during vegetative period; 1965 much below normal moisture, near normal temperature during vegetative period.

Table 31)-2-Effect of weed competition on yield of wheats of differing morphologies

\begin{tabular}{lccccc}
\hline & \multicolumn{2}{c}{ Location A } & & \multicolumn{2}{c}{ Location B } \\
\cline { 2 - 3 } \cline { 5 - 6 } & Yield & Height & & Yleld & Height \\
\hline & $\mathrm{kg} / \mathrm{ha}$ & $\mathrm{cm}$ & & $\mathrm{kg} / \mathrm{ha}$ & $\mathrm{cm}$ \\
Check I & 3,767 & 114 & & 3,329 & 114 \\
Short upright & 3,787 & 86 & & 2,132 & 79 \\
Tall leafy* & 3,181 & 112 & & 3,094 & 119 \\
Check II & 4,029 & 112 & 2,885 & 114 \\
\hline
\end{tabular}

* Developed at Location B. Location A - Broad-leafed weeds controlled chemically; Location B - Broad-leafed weeds present.

showed little reduction in yield at the weedy location. At one location the results would indicate that the short upright variety should be discarded immediately, while the results at the other location would indicate future possibilities.

These observations emphasize the fact that selections made from a breeding program reflect the environment in which the nursery was evaluated. In the example cited here, weed competition at the one location represented a selection pressure in favor of tall leafy types, i.e. performance was based primarily on the plants' ability to compete with weeds. However the competition with weeds in this instance was no less of a deter rent in selecting for yield than was the selection and evaluation of rice (Oryza sativa L.) strains under a low nitrogen regime (as indicated by previous speakers) or, in all likelihood, the $100 \mathrm{~cm}$ (40-inch) row commonly used in corn (Zea mays L.) breeding programs. 